\title{
MODELOS ASSOCIATIVISTAS DE GESTÃO DE SANEAMENTO RURAL
}

\author{
Marcelo Ximenes Teles da Roza ${ }^{1}$ \\ Jamile Amorim Araújo ${ }^{2}$
}

\begin{abstract}
RESUMO: Os investimentos em saneamento básico, no Brasil, historicamente foram concentrados nos grandes centros urbanos. Deixando grande parte da população rural e dos pequenos municípios, sem acesso aos serviços públicos. Superar o passivo acumulado em saneamento rural, levando em consideração as especificidades desses territórios é o grande desafio das políticas públicas na área de saneamento. Desse modo o objetivo geral da pesquisa é fazer uma discussão sobre o saneamento básico rural no Brasil e de forma mais especifica deseja-se apresentar um modelo de gestão dos recursos hídricos e saneamento rural pautado no associativismo e na autogestão, tendo como foco o SISAR (Sistema Integrado de Saneamento Rural) aplicado com êxito e reconhecimento no Estado do Ceará.
\end{abstract}

Palavras-chave: Saneamento Rural; Gestão de Recursos Hídricos; Associativismo; Salubridade Ambiental.

\section{ASSOCIATIVE MODELS OF RURAL SANITATION MANAGEMENT}

ABSTRACT: Investments in basic sanitation in Brazil have historically been concentrated in large urban centers. Leaving much of the rural population and small municipalities without access to public services. Overcoming the accumulated liabilities in rural sanitation, taking into account the specificities of these territories is the major challenge for public policies in the area of sanitation. Thus, the general objective of the research is to discuss rural basic sanitation in Brazil and, in a more specific way, we want to present a water resources management and rural sanitation model based on associativism and self-management, focusing on SISAR ( Integrated Rural Sanitation System) successfully applied and recognized in the State of Ceará.

Keywords: Rural Sanitation; Water Resources Management; Associations; Environmental Health.

\footnotetext{
${ }^{1}$ Ciências Econômicas (UFC). Mestre em Economia Rural (MAER-UFC). Professor do curso de Ciências Econômicas (URCA). E-mail: marceloximenes451@hotmail.com.

${ }^{2}$ Economista (URCA). E-mail: jamile.milinha14@gmail.com.
} 


\section{INTRODUÇÃO}

É comum nos dias atuais a preocupação com a sustentabilidade e desenvolvimento dos povos. Um ponto crucial de sustentação desses dois pilares é, sem dúvida, a qualidade de vida das pessoas. Esta por sua vez encontra-se completamente entrelaçada as condições sociais, 'econômicas, ambientais e culturais em que os indivíduos estão inseridos. Desse modo é de extrema importância para o desenvolvimento do ser humano, e por sua vez para o desenvolvimento das sociedades, a preocupação com o meio onde as pessoas vivem. Assim sendo, podemos dizer que um ambiente limpo, arejado, habitável, respirável, ou seja, um habitat saneado é condição básica para se atingir uma qualidade de vida mínima que propicie um real desenvolvimento sustentável de qualquer comunidade.

É bem verdade que a atenção com o saneamento dos ambientes não é uma coisa nova e sempre esteve ligada a evolução civilizatória. Os registros históricos mostram o reconhecimento por diversas civilizações que sanear os ambientes traria benefícios para sociedade e o padrão de vida geral da população. Hoje, porém, é consenso que o processo de saneamento é básico para qualquer nível respeitável de desenvolvimento, isso dado o seu caráter multidimensional, facilmente percebido quando entendemos o saneamento como um conjunto de medidas que visa preservar ou modificar as condições do meio ambiente buscando prevenir doenças e promover a saúde, melhorar a qualidade de vida da população, a produtividade do indivíduo e facilitar a atividade econômica (INSTITUTO TRATA BRASIL, 2016).

Segundo Turrolla (2005), no Brasil são produzidos e distribuídos 44 milhões de $\mathrm{m}^{3}$ por dia de água, destes, 39 milhões de $\mathrm{m}^{3}$ de água são retornados sem 0 devido tratamento. O manejo irresponsável dos sistemas de saneamento gera impactos ambientais, problemas de poluição e contaminação de águas, comprometendo o fornecimento futuro dos recursos hídrico.

A avaliação do sistema de saneamento básico é imprescindível diante de fortes impactos na saúde e qualidade de vida das pessoas. É urgente uma gestão dos recursos hídricos integrada, participativa, e eficiente, que otimize o aproveitamento de recursos, reduzindo ao máximo os eventuais conflitos. Vale ressaltar que por sistema de saneamento básico, entende-se existir uma integração dos aspectos ligados ao: abastecimento de água, coleta e tratamento de esgotos 
sanitários, coleta e tratamento de resíduos sólidos e a drenagem urbana, aliados ao meio ambiente.

Uma em cada três pessoas do planeta, não tem acesso a saneamento básico. Estima-se que mais de 750 milhões de pessoas não tem acesso a água potável, que aproximadamente 2,5 bilhões de pessoas ainda não têm instalações sanitárias adequadas e que $14 \%$ (cerca de 1 bilhão) da população mundial não tem nenhuma forma de instalação sanitária. É importante registrar as disparidades existentes não só entre as diferentes regiões do mundo, mas também entre áreas urbanas e rurais, visto que desse 1 bilhão de indivíduos sem nenhum tipo de acesso a instalações sanitárias, 90\% vivem em áreas rurais (REZENDE, 2018). Esse panorama é bastante preocupante dado a estreita relação entre saneamento e saúde. Teixeira e Guilhermino (2006) identificaram uma forte associação entre a precariedade dos serviços sanitários e a mortalidade infantil para todas as idades, em um estudo feito nos estados brasileiros.

Os impactos do saneamento básico adequado vão além das questões relacionadas a saúde. O setor econômico também é bastante afetado por uma gestão eficiente de sistema de saneamento. É logico que um indivíduo saudável e com qualidade de vida produz muito mais, afetando a produtividade das empresas. Outro impacto importante é exatamente no sistema de saúde, que fica bem menos sobre carregado, podendo aplicar recursos em outros casos mais urgentes. Porém um fator muito importante nesse quesito é que a indústria do saneamento requer bastante mão de obra, nesse sentido, a expansão do sistema de saneamento básico afeta diretamente na geração de empregos, gerando um ciclo virtuoso na economia. Segundo TRATA BRASIL (2018) entre 2004 e 2016, o investimento em saneamento no Brasil passou de $R \$ 3,1$ bilhões para $R \$ 11,4$ bilhões, o que indica um crescimento de $11,5 \%$ ao ano. Na média do período, a receita operacional total foi de $R \$ 48,8$ bilhões por ano, com taxa de crescimento médio de $10,1 \%$ ao ano. Estima-se ainda que, na média do período, o setor gerou quase 69 mil empregos diretos por ano na construção civil e pagou uma renda média de aproximadamente $\mathrm{R} \$ 14$ milhões, além de ter contribuído em torno $\mathrm{R} \$ 9$ bilhões em impostos.

Outra característica marcante na indústria do saneamento é a presença de custos fixos elevados em capital, o que consequentemente lhe a associa à ideia de monopólio natural, trazendo um dilema entre a eficiência produtiva e a eficiência a 
locativa, além de um baixo incentivo ao investimento, principalmente privado (Turrolla,2002). Desse modo o que se verifica é predominância do modelo de gestão público e local.

No Brasil o saneamento básico é um direito reconhecido pela Constituição Federal e determinado pela Política Nacional de Saneamento Básico - Lei no․ 11.445/2007 - como o conjunto dos serviços, infraestrutura e instalações operacionais de abastecimento de água, esgotamento sanitário, limpeza urbana, drenagem urbana, manejos de resíduos sólidos e de águas pluviais (INSTITUTO TRATA BRASIL, 2016) De acordo com a Lei do Saneamento Básico, no $11.445 / 2007$, todos os municípios deveriam, até dezembro de 2013 , ter elaborado os seus Planos Municipais de Saneamento, documento condicionante para o recebimento de recursos a fundo perdido ou financiados pela União (BRASIL, 2007). Os serviços públicos de saneamento no Brasil podem ser oferecidos por órgãos da administração direta ou indireta. Existem atualmente no país três categorias prestadoras dos serviços de água e esgoto, sendo elas locais, privadas ou estaduais/regionais.

O saneamento básico rural é, sem dúvidas, o maior desfio da busca de universalização dos serviços. Representando $70 \%$ do déficit nacional no acesso ao sistema de saneamento adequado, a população rural, que segundo o IBGE (2010) totaliza aproximadamente 30 milhões de pessoas e que deste $25 \%$ vivem em condições de extrema miséria, é formada por comunidades rurais, quilombolas e assentados. A falta de atenção do setor público para essa área ficou evidente no Plano Nacional de Saneamento (PLANASA), que desprezou as ações em áreas rurais. (SILVEIRA, 2013). Políticas públicas desarticuladas, fragmentadas e marcada por forte instabilidade institucional, além da inadequada tecnologia de saneamento básico, muitas vezes transplantadas das áreas urbanas sem levar em conta as características peculiares do meio rural, são os principais entraves ao caminho da universalização dos serviços dessas regiões. Somente em 2013 foi aprovado o Programa nacional de saneamento rural, com o objetivo de diminuir o déficit de investimento no setor e superar o passivo acumulado em saneamento rural. Os investimentos em saneamento básico, no Brasil, historicamente foram concentrados nos grandes centros urbanos. Deixando grande parte da população rural e dos pequenos municípios - sem acesso aos serviços públicos. Superar o passivo 
acumulado em saneamento rural, levando em consideração as especificidades desses territórios é o grande desafio das políticas públicas na área de saneamento.

O desinteresse no assunto é refletido no meio acadêmico, visto que raro são os trabalhos que se concentram em estudar o saneamento rural. Em uma pesquisa do Banco Mundial efetuada no ano de 2010 feita com os diversos modelos de prestadores de atendimento específico do meio rural, dentre eles, um chamou a atenção pelo caráter associativo e de autogestão, o Modelo SISAR- Sistema Integrado de Saneamento Rural. Desse modo, o objetivo do presente trabalho é apresentar o modelo de gestão de recursos hídricos no meio rural adotado pelo SISAR, mais especificamente pelo SISAR do Estado do Ceará, cujo pioneirismo se em meados da década de 90.

A relevância do presente trabalho, além de servir de apoio as políticas públicas, também pode ser afirmada no instante que se propõe em apresentar, um Modelo de Gestão Hídrica e de Saneamento Rural, adotado pelo Sistema Integrado de Saneamento Rural-SISAR no Estado do Ceará, com um caráter inovador, reconhecido nacionalmente, que beira a auto sustentabilidade e que traz a sociedade a interagir no processo de gestão.

\section{REFERENCIAL TEÓRICO}

\subsection{SANEAMENTO RURAL E ALGUNS MODELOS DE GESTÃO}

Ainda que detendo a maior reserva de água doce do mundo, cerca de $12 \%$ da disponibilidade total do planeta, nosso país não consegue distribuir este bem natural para a sua população e vê no abastecimento e no saneamento o reflexo das desigualdades sociais existentes no seu território. Para o melhor entendimento se faz necessário tecer considerações quanto a diferença entre os termos saneamento ambiental e salubridade ambiental. Esses dois conceitos estão intimamente ligados, porém se distingue por uma linha tênue. Em primeiro lugar, salubridade é uma qualidade do ambiente. Já o saneamento é um conjunto de medidas que busca alcançar a salubridade ambiental. Desse modo podemos entender o saneamento como um meio, enquanto que a salubridade é um fim. A salubridade vai além do saneamento. Viver em um ambiente salubre é ter acesso ao saneamento, mas também a saúde, educação, qualidade de vida etc. 
Embora a trajetória da área de abastecimento de água e esgotamento sanitário no Brasil talvez pudesse ter experimentado uma evolução mais virtuosa, em termos do acesso da população aos serviços e de proteção à saúde humana e ao ambiente, é importante reconhecer que diversas localidades tiveram a capacidade de se sobressair pela qualidade do serviço prestado. Essa qualidade do serviço pode ter várias características, como naqueles serviços que conseguiram atingir a universalização; nos serviços que, mesmo ainda não a atingindo, desenvolvem políticas públicas inovadoras que colaboram nessa direção, ou em soluções tecnológicas apropriadas que têm o potencial da inclusão social.

O saneamento ambiental é um serviço público fundamental à promoção da saúde e a prevenção do meio ambiente, sendo e acesso aos serviços de abastecimento de água e esgotamento sanitário um direito social básico, assegurado constitucionalmente a todos os cidadãos brasileiros. O Brasil possui cerca de 5.570 municípios e destes $81,5 \%$ tem seus serviços de saneamento concedidos a empresas estaduais. Contudo, o atendimento destas empresas não atinge todas as localidades rurais fora da sede urbana, o qual fica sob a responsabilidade do município, sendo que este, por ter pouca capacidade de gestão em serviços de água e saneamento, torna o atendimento rural pouco sustentável.

Em uma pesquisa do Banco Mundial efetuada no ano de 2010 feita com os diversos modelos de prestadores de atendimento específico do meio rural, entre as quais se incluem: Sisar/Ceará; Central na Bahia; Sisar do Piauí; CONISA (Consórcio Intermunicipal de Saneamento) no Rio Grande do Norte; COPASA Serviços de Saneamento Integrado do Norte e Nordeste em Minas Gerais. Observase que neste universo as unidades do Ceará, Bahia e Piauí são do tipo "Sisar e Central", que tem a mesma característica institucional embora com nomes diferentes.

A CONISA é um consórcio intermunicipal, implantado pela Companhia de Água e Esgoto do Rio Grande do Norte - Coern, em 2004, com a Associação de Moradores de Riacho do Bom Pasto no município de Serrinha. O modelo consiste em fazer com que a própria comunidade cuide do abastecimento acompanhado da empresa. Ela deve ser legalmente constituída e assinar contrato de prestação de serviços. Assinado o contrato, que pode ser renovado a cada dois anos, os consumidores estabelecem valor a ser pago por morador, incluindo as despesas com a manutenção do serviço. Participam do CONISA, o estado e sete municípios. 
O consórcio é integrante da administração pública dos municípios associados. O objetivo do CONISA é a promoção de ações voltadas para a gestão sustentada dos sistemas de abastecimento de água. O Projeto do Sistema Adutor foi a solução encontrada para resolver o problema de escassez de água na região. A adutora garante o abastecimento de água, sendo que, a distribuição, passa a ser gerenciada pela CONISA. O consórcio deve dar a assistência técnica a essas associações, ajudando no controle, fiscalização e distribuição de água, em todas as comunidades rurais, já nos outros modelos, as entidades coordenadoras não contam com participação do poder público e assumem a forma de ONGs.

A COPANOR é uma empresa estadual subsidiária da COPASA (Companhia Estadual de Água e Esgoto) específica para pequenas localidades no norte do Estado de Minas Gerais, é uma empresa pública subsidiária da COPASA, criada pelo Governo de Minas, em 2007, para atender as regiões Norte e Nordeste do Estado com os serviços de abastecimento de água tratada, coleta e tratamento de esgotos sanitários e construção de módulos sanitários e de serviços domésticos em todas as casas desprovidas dessas instalações. Seu objetivo é Implantar sistemas de abastecimento de água, coleta e tratamento de esgoto em todas as localidades com população entre 200 e 5.000 habitantes no Norte e Nordeste de Minas, operar os sistemas de água e esgoto com padrão de portabilidade de acordo com as recomendações da Organização Mundial de Saúde e praticar tarifas compatíveis com a realidade local. (PAIVA, 2013, p. 4)

Qualquer que seja a análise, no entanto, a situação da área de saneamento no Brasil mostra com nitidez uma evolução muito acanhada na direção de um ambiente mais compatível com a realidade democrática do país, sobretudo quando se compara com a evolução de outros setores públicos, a partir da redemocratização de meados da década de 1980. Assim, com maior velocidade e eficiência, a participação popular e o controle social legitimaram-se nas áreas de saúde, de meio ambiente, de política urbana e de recursos hídricos. A própria área de recursos hídricos, ao adotar a bacia hidrográfica como unidade de planejamento e estabelecer os comitês das bacias para a sua gestão, mostra sinais inequívocos de fortalecimento do poder local. Este passivo de democratização, portanto, ainda acompanha a área de saneamento, talvez encontrando explicação na resistência 
dos grupos de interesse nele instalados em ter seu poder controlado. (PAIVA, 2013, p. 6)

\subsection{O SANEAMENTO BÁSICO NO ESTADO DO CEARÁ E O PIONEIRISMO NO MODELO SISAR DE GESTÃO}

No Estado do Ceará as questões relacionadas ao saneamento básico são agravadas pela sua posição geográfica. Com mais de $90 \%$ de seu território no semiárido brasileiro o Estado sofre com os efeitos da seca. Apesar de ser um estado pobre, o Ceará realizou ao longo dos anos uma relativa infraestrutura hídrica capaz de suportar uma estiagem mais longa, porém segundo dados da Companhia de Gestão de Recursos Hídricos (COGERH) os reservatórios já estão no seu limite e a situação de abastecimento é precária, diante de 6 anos de seca. Segundo a Secretária das Cidades (2017), em 2017 o Estado tinha 92\% da população urbana com acesso a água tratada e 39\% com acesso a sistema de esgoto. Já a realidade do meio rural era bem diferente, apenas $52 \%$ da população tenha água tratada e 27\% tinha acesso a esgotamento sanitário. Ainda em 2017 apenas 31\% dos municípios cearenses tinham elaborado um plano municipal de saneamento básico. Em 2016 foi publicada uma lei que instituiu a Política Estadual de Abastecimento de Água e Esgotamento Sanitário, esta lei traz diretrizes que respeitam as condições particulares do Estado, especialmente no tocante ao saneamento rural. Nas áreas urbanas a maior prestadora de serviço é a Companhia de água e esgoto do Estado do Ceará. Já no meio rural os sistemas de abastecimento de água no Ceará são mantidos pelos prestadores do serviço de saneamento, notadamente prefeituras municipais, Serviços Autônomos de Água e Esgoto (SAAEs), Associações Comunitárias e o Sistema Integrado de Saneamento Rural (SISAR), sendo os dois últimos os principais prestadores de serviço da zona rural. Em 2016 o Estado aderiu ao Sistema de Informação em Água e Saneamento Rural - SIASAR, tornando-se o primeiro Estado a utilizar esse sistema no Brasil.

Ainda em relação ao Estado do Ceará, uma experiência inovadora no que diz respeito a gestão de recursos hídricos no meio rural foi a criação do Sistema Integrado de Saneamento Rural (SISAR). Criado pela Cagece em 1996, em parceria com o banco alemão Kreditanstallt fü Wiederaufbau - KFW, o projeto é uma entidade privada sem fins lucrativos que gerencia sistemas de abastecimento de 
água. Tem como público alvo a população residente em comunidades rurais atendidas com saneamento rural. O SISAR já é destaque nacional em gestão de saneamento rural, tendo sido referência para outras experiências no semiárido brasileiro. O modelo apresenta bases associativistas que une usuários e a população local, o SISAR, o Município e Governo do Estado em um grande pacto pela sustentabilidade dos sistemas, garantindo assim sua permanência. Daí,a grande relevância das ações sociais dos SISAR, em apoio constante às associações locais, às comunidades e sistemas, assim como, as ações socioambientais e de controle social, fundamentais ao desenvolvimento do modelo. (ROCHA, 2013).

\section{METODOLOGIA}

A área geográfica de estudo abrange todos 184 municípios do Ceará. O Estado possui uma área de 148.920,538 $\mathrm{km}^{2}$ com densidade geográfica de (hab/ $\mathrm{km}^{2}$ ) de 56,76 sendo a população estimada para o ano de 2010 de 8.452.381 (IBGE, 2011). Limita-se a leste com os Estados do Rio Grande do Norte e Paraíba, ao sul com o Estado de Pernambuco e a oeste com o Estado do Piauí. Ao Norte é banhado pelo oceano Atlântico numa extensão de $573 \mathrm{~km}$, com litoral pouco recortado, onde aparecem planícies costeiras e praias cobertas por dunas de beleza singular. Politicamente está dividido em 14 mesorregiões: Cariri, Centro Sul, Grande Fortaleza, Litoral Leste, Litoral Norte, Litoral Oeste, Maciço de Baturité, Serra da Ibiapaba, Sertão Central, Sertão de Canindé, Sertão de Sobral, Sertão do Crateús, Sertão dos Inhamuns, Vale do Jaguaribe. No Ceará os problemas relacionados à escassez de água são corriqueiros, visto que $92 \%$ de seu território está no semiárido sendo este Estado vítima de grandes secas ao longo de sua história. Nos últimos anos o Ceará tem se destacado realizando uma serie de investimentos em infraestrutura hídrica o que o fez torna-se referência nacional em gestão dos recursos hídricos. Desse modo, a escolha do estado do Ceará para o laboratório da pesquisa parece ser bastante significativa para o entendimento dos desafios que 0 meio rural enfrenta nas questões de saneamento básico.

Para atingir nossos objetivos e realizar um estudo de caso do Modelo De Gestão Hídrica e de Saneamento Rural, adotado pelo Sistema Integrado de Saneamento Rural-SISAR no Estado do Ceará, tomaremos por base a Bacia do 
Alto Jaguaribe - BAJ, com sede do município de Acopiara-CE, por ser uma região com recursos hídricos limitados, de grande extensão territorial e bastante diversificada em relação aos demais mananciais. As informações necessárias para esse objetivo serão adquiridas através de visitas técnicas nos Escritórios do SISAR, entrevistas com gestores e usuários.

Como maior fonte de pesquisa foram utilizados, além da literatura existente, dados do Banco Internacional de Desenvolvimento (BID), do Gesar, sistema do Sisar, além da análise de documentos, registros históricos e dados referentes à área de estudo. Os dados primários foram retirados do sistema de software, disponibilizados pelo Sisar, Posseidon da JF Consultores que administra o banco de dados desta federação e visita técnica.

A pesquisa buscou analisar, entre outras questões relevantes, o modo como se deu o surgimento e o desenvolvimento desse modelo de gestão atuando na Bacia do Alto Jaguaribe. Iniciando, de forma geral, com uma análise do cenário do território cearense, região extremamente seca e com pouca incidência de chuvas, a forma como se deu a implantação dos projetos e estações de abastecimento de água, inicialmente sem gestão autossustentável e com sérios problemas internos organizacionais, a importância e as condições dos sistemas de abastecimento de água no estado Ceará.

\section{O MODELO DE GESTÃO SISAR NO CEARÁ}

É justamente num vácuo institucional que, surge no Nordeste brasileiro, no final da década de 1990 e início dos anos 2000, Programas de Saneamento Rural estruturados a partir da autogestão do sistema de água e esgoto por associação de moradores em parceria com as Companhias Estaduais do setor, com o financiamento do banco alemão Kreditanstallt Fü Wiederaufbau - KFW, do Banco Mundial, através do Projeto São José e ainda aporte federal através da Funasa Fundo Nacional de Saúde, Governo do Estado e Prefeituras. O objetivo inicial do programa era implantar sistemas de abastecimento d'água e esgotamento sanitário em um número definido de pequenas localidades rurais. $\mathrm{Na}$ implantação dos sistemas, as localidades a serem beneficiadas foram selecionadas sem levar em consideração os níveis de organização das comunidades. Estes eram extremamente diversificados: algumas já estavam muito bem estruturadas, com associação 
comunitária constituída, diretoria eleita e até alguns projetos na área social em andamento; já outras estavam completamente desarticuladas.

Com isso, se observou que em algumas localidades estes projetos tiveram o papel de indutor da organização comunitária e para isso eram as associações de moradores que deveriam fazer a administração de seus próprios sistemas. Estas dificuldades fariam com que o sistema caminhasse rapidamente para um estado de deterioração. Surgindo assim a necessidade de se criar organizações que não tivessem relação direta com as comunidades, que coordenassem os trabalhos de manutenção dos sistemas implantados garantindo a continuidade dos benefícios. Assim, em 1994, o programa é reestruturado e surge o Sistema Integrado de Saneamento Rural - Sisar-CE.

O Sisar, entidade que congrega associações comunitárias com Sistema de Abastecimento de Água e coleta de Esgoto, localizadas na mesma bacia hidrográfica e nas circunvizinhas, no Estado do Ceará, é uma Associação Civil, de direito privado, sem fins econômicos, com personalidade jurídica, patrimônio e administração própria, regida pelo Código Civil Brasileiro. (Leis 10.406/2002 e 11.127/2005) e pelas normas legais aplicáveis. O modelo comunitário federativo no Ceará com o nome de Sisar trabalha na tentativa de atender a portaria $\mathrm{n}^{\circ} 2.914$, de 12 de dezembro de 2011, apoiado na Lei 9.433/1997 que estabelece as diretrizes nacionais para o saneamento básico e para uma política nacional de saneamento. Tem como princípio a universalização do acesso à água tratada, institui a Política Nacional de Recursos Hídricos que dispõe sobre os procedimentos de controle e de vigilância da qualidade da água para consumo humano e seu padrão de portabilidade. Esta lei no capítulo referente à política, traz entre suas diretrizes a garantia de meios adequados para o atendimento da população rural dispersa, inclusive, mediante a utilização de soluções compatíveis com suas características econômicas e sociais peculiares. Estas experiências vêm apresentando resultados satisfatórios na extensão dos serviços prestados. (SILVA; CORTEZ, e RIBEIRO, 2013).

Desde o início de sua implantação a participação dos governos municipais é praticamente nenhuma. Os recursos financeiros necessários à implantação, estruturação e operação de cada Sisar deverão advir inicialmente da Companhia de Água e Esgoto do Estado do Ceará - Cagece e do Banco Internacional para 
Reconstrução e Desenvolvimento - BIRD (Banco Mundial), já que a arrecadação inicial prevista não será suficiente para cobrir os custos de implantação e estruturação dos escritórios do Sisar. A Cagece idealizou, subsidiou e mantém essa parceria com o modelo de gestão. Cada Sisar é responsável pela administração do patrimônio instalado pelo Programa de Saneamento Rural, incluindo bens físicos ou financeiros que venham a receber do governo ou de particulares, bem como os recursos decorrentes das taxas pela prestação de serviços de saneamento, como mostra na Figura 1. Enquanto que o papel da Cagece é o de planejar, projetar e construir os sistemas, o papel do Sisar é de administrar e operar estes sistemas, de forma conjunta e participativa, garantindo sua continuidade. Em 2013, segundo dados da Cagece, o Sisar estava presente em 133 municípios e 719 localidades. Os sistemas constam de 2.150.546 milhões de metros de rede de água e 94.150 ligações de água. (SILVA; CORTEZ, e RIBEIRO, 2013, p.3).

O primeiro Sisar foi implantado na Bacia do Acaraú e Coreaú, na região de Sobral. Hoje existe um Sisar para cada umas das oito bacias hidrográficas do Ceará, um total de aproximadamente 405 mil pessoas beneficiadas com o sistemas nas bacias hidrográficas, são elas: BAC - Bacia do Acaraú e Coreaú (com sede em Sobral); BCL - Bacia do Curú e Litoral (com sede em Itapipoca); BME - Bacia Metropolitana (com sede em Fortaleza); BPA - Bacia do Parnaíba (com sede em Crateús); BBA - Bacia do Banabuiú (com sede em Quixadá); BBJ - Bacia do Baixo e médio Jaguaribe (com sede em Russas); BSA - Bacia do Salgado (com sede em Juazeiro do Norte) e a BAJ - Bacia do Alto Jaguaribe (com sede em Acopiara), todas independentes entre si, mas são gerenciadas, coordenadas e fiscalizadas pela Cacege. Cada um desses constitui uma ONG - Organização Não Governamental, formadas pelas próprias associações comunitárias que representam a população atendida, com a participação da Cagece. Segundo o gerente de saneamento rural da Cagece, Hélder Cortez (2014, p. 1) "[...] a Cagece, através da Gerência de Saneamento Rural (Gesar), implanta e monitora os sistemas de abastecimento de água. Depois de construídos esses sistemas rurais, é preciso gerenciá-los para que não fiquem sucateados e aí entram as ONGs, chamadas Sisar". (XVI Encontro Nacional dos Geógrafos, 2010).

Cada unidade é autônoma com personalidade jurídica própria. O único vínculo entre elas se dá pela ação da Cagece, através da Gesar - Gerência de Saneamento Rural, na elaboração e avaliação de indicadores mensais, na 
organização trimestral de reuniões para troca de experiências, supervisão e aporte de especialistas na área e avaliação de metas. Para a realização de seus objetivos, - Sisar constitui uma equipe executiva de caráter técnico amparadas por um Gestor Técnico qualificado na área, onde a partir do ganho de escala obtido, são feitas as ações mais complexas de manutenção e controle de qualidade da água; o suprimento de insumos diversos, o faturamento e o fluxo financeiro são de responsabilidade do Gestor Administrativo Financeiro e ainda a Gestora de Capacitação Social em termos permanentes, a medição de conflitos e a educação sanitária, como detalha a Figura 3. Segundo Rocha (2013, p. 18) o modelo permite ainda a elevação dos graus de sustentabilidade da associação local e o seu aprimoramento associativo, auxiliando em alguns casos na formulação de outros projetos sociais e produtivos para a comunidade.

Figura 1. Estrutura de apoio: Cagece - Sisar

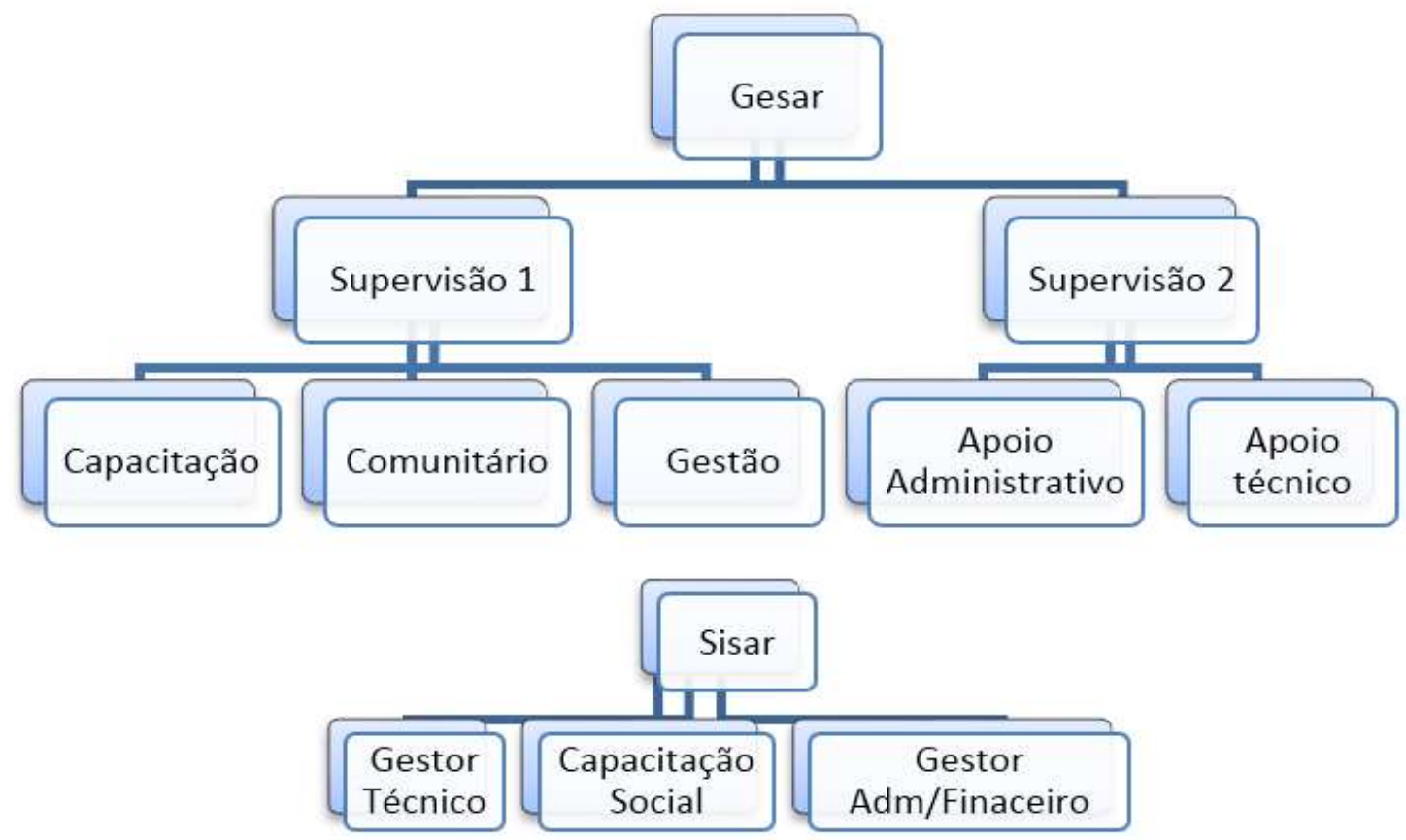

Fonte: Elaborado pelo autor

Seu desempenho financeiro é avaliado por um sistema de metas de desempenho e eficiência a que estão submetidas todas as unidades do Sisar e cujo monitoramento é feito pela Gesar. Os serviços de água têm padrão que consiste de: distribuição no domicílio; tratamento e controle de qualidade; e ligação com hidrômetro. O serviço de esgotamento coletivo é oferecido somente em 15 
localidades da região de Sobral no Ceará, não havendo este serviço nas demais regiões.

Apesar das dificuldades que ainda passam alguns desses sistemas para adquirir independência financeira, necessitando de auxilio de esferas do governo e do exterior, o objetivo de autossustentabilidade leva à reformulação das práticas de consumo de água, algo que é fundamental no interior do Nordeste brasileiro. A capacidade da população para a administração e manutenção dos sistemas feita em algumas experiências também merece destaque, tendo em vista que torna a comunidade independente de atores externos para a realização de tarefas primordiais e no trato administrativo. Seu caráter inovador encontra-se não somente na expansão dos serviços de saneamento, mas também nas novas formas de organização da população que esses sistemas solicitam. Os novos sistemas de gestão de Saneamento em áreas rurais apresentados são experiências que, de fato, estimulam a melhoria do quadro socioeconômico do interior do Nordeste brasileiro, além da expansão de sua repercussão por todo o Brasil.

O primeiro Sisar foi implantado na Bacia do Acaraú e Coreaú, na região de Sobral. Hoje existe um Sisar para cada sistema de bacias hidrográficas do Ceará, todas independentes entre si, porem gerenciadas, coordenadas e fiscalizadas pela Cacege e tendo um total de aproximadamente 405 mil pessoas beneficiadas. Os sistemas nas bacias hidrográficas são apresentados abaixo e a figura 2 ilustra suas devidas posições geográficas: 
Figura 2- Localização dos Sisar's por Bacias Hidrográficas

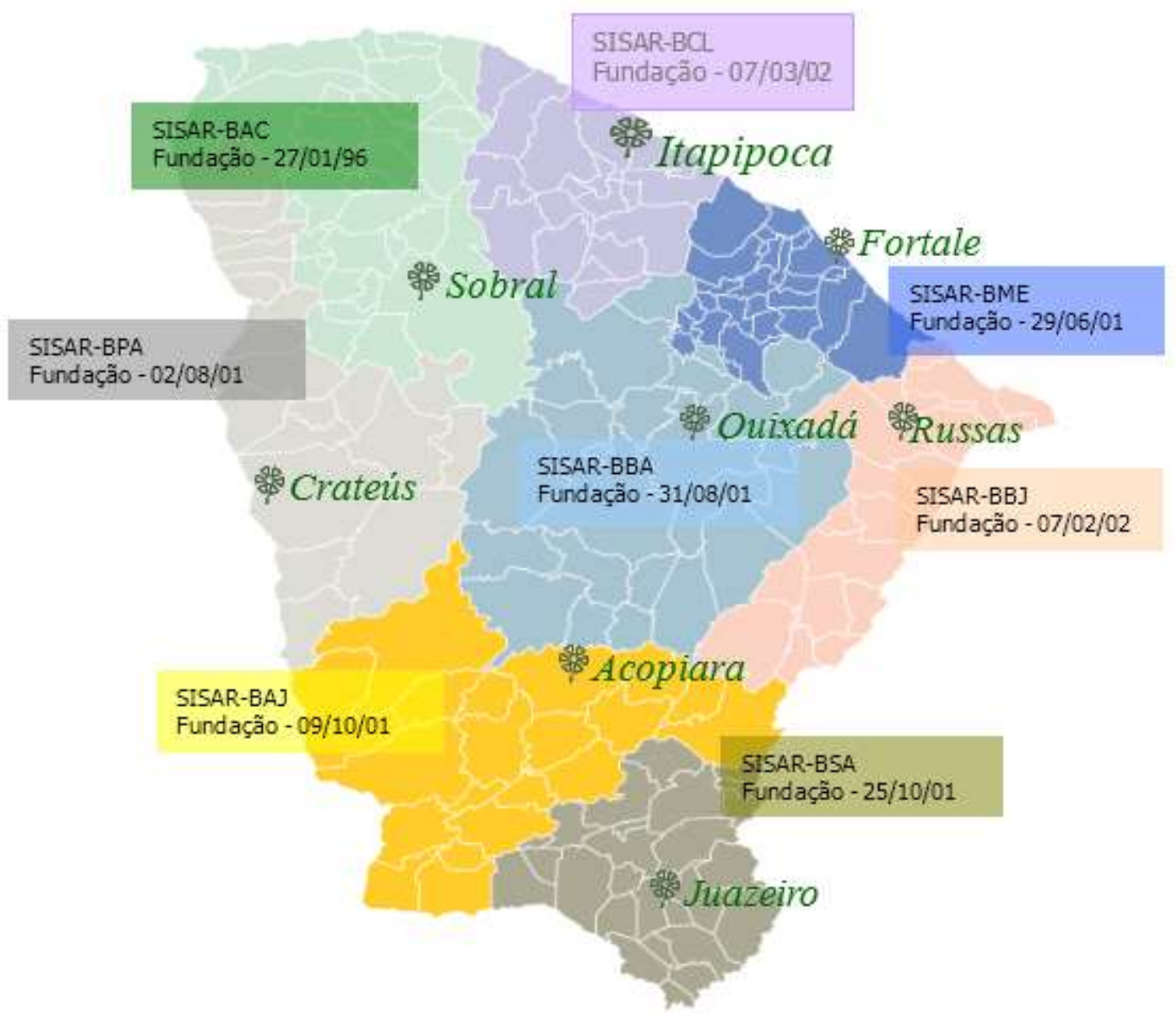

Fonte: CAGECE, 2010

BAC - Bacia do Acaraú e Coreaú (com sede em Sobral);

BCL - Bacia do Curú e Litoral (com sede em Itapipoca);

BME - Bacia Metropolitana (com sede em Fortaleza);

BPA - Bacia do Parnaíba (com sede em Crateús);

BBA - Bacia do Banabuiú (com sede em Quixadá);

BBJ - Bacia do Baixo e médio Jaguaribe (com sede em Russas);

BSA - Bacia do Salgado (com sede em Juazeiro do Norte)

BAJ - Bacia do Alto Jaguaribe (com sede em Acopiara),

Cada um desses SISAR, constitui uma ONG - Organização Não Governamental, formadas pelas próprias associações comunitárias que representam a população atendida, com a participação da Cagece. Segundo o gerente de saneamento rural da Cagece, Hélder Cortez (2014, p. 1) "[...] a Cagece, através da Gerência de Saneamento Rural (Gesar), implanta e monitora os sistemas de abastecimento de água. Depois de construídos esses sistemas rurais, é preciso 
gerenciá-los para que não fiquem sucateados e aí entram as ONGs, chamadas Sisar". (XVI ENCONTRO NACIONAL DOS GEÓGRAFOS, 2010).

Cada unidade é autônoma com personalidade jurídica própria. O único vínculo entre elas se dá pela ação da Cagece, através da Gesar - Gerência de Saneamento Rural, na elaboração e avaliação de indicadores mensais, na organização trimestral de reuniões para troca de experiências, supervisão e aporte de especialistas na área e avaliação de metas.

Apesar de intensos esforços nos últimos dez anos no sentido de tornar mais eficiente o uso e o gerenciamento dos recursos hídricos em todo o Estado do Ceará, a relação demanda/oferta de água continua em desequilíbrio. $\mathrm{O}$ crescimento populacional e a urbanização são fatores relevantes na demanda por água; à oferta, por outro lado, estão associadas inúmeras incertezas inerentes ao processo hidrológico, causadas pela variabilidade natural das vazões de seus rios, o que torna a determinação da quantidade de água efetivamente disponível muito imprecisa. A Bacia do Alto Jaguaribe apresenta representativa heterogeneidade tanto no que diz respeito à distribuição espaço-temporal da precipitação quanto ao escoamento de suas águas, para os diversos municípios que a compõem. Localiza-se na porção sudoeste do Estado do Ceará, limita-se a oeste com o Estado do Piauí e ao sul com o Estado de Pernambuco. Das cinco sub-bacias que compõem a bacia do rio Jaguaribe (Alto, Médio e Baixo Jaguaribe, Banabuiú e Salgado) é a que possui maior região hidrográfica, sendo, também, a maior do Estado, mas tal distribuição não serve, no entanto, como reservas interanuais, pois, quando da ocorrência de anos secos consecutivos, tais reservatórios não apresentam volumes para o atendimento às demandas.

A Política Estadual de Recursos Hídricos tem se destacado no segmento estruturante por realizar ações de preservação de água através da construção de açudes interanuais, e de transferências de água, sejam em canais ou adutoras que visam assegurar o abastecimento humano e gerar desenvolvimento na região, com a oferta de água para a produção na indústria e na agropecuária. A atual política de águas do Ceará enfatiza a gestão da demanda, englobando formalização do direito de uso, cobrança de água, campanhas educativas e a descentralização das decisões.

O Sisar-BAJ - Sistema Integrado de Saneamento Rural da Bacia do Alto Jaguaribe foi fundado em 09 de outubro de 2001, com sede no município de 
Acopiara, inicialmente com 05 comunidades e em 04 municípios: Acopiara, Arneiroz, Orós e Tauá. A Bacia do Alto Jaguaribe abrange os municípios de: Acopiara, Arneiroz, Aiuaba, Catarina, Jucás, Saboeiro, Iguatu, Quixelô, Icó, Orós, Tauá, Parambu, Potengi, Antonina do Norte, Cariús, Assaré, Salitre, Tarrafas, Cariús, Iguatu, Campos Sales e Araripe. Com a exceção de: Quixelô, Tarrafas e Parambu, o Sisar-BAJ conta hoje com 107 comunidades filiadas, 173 localidades atendidas, 14.374 ligações, um total de 54.622 consumidores, localizados em 17 municípios dos 20 que compõem a Bacia do Alto Jaguaribe.

A equipe técnica de pessoal do Sisar-BAJ é composta de 17 funcionários contando com um Responsável Administrativo - Financeiro, um Responsável Técnico, uma Responsável de Capacitação Social, 02 eletromecânicos, 01 eletricistas, 02 agentes administrativo, 03 agentes comerciais, 01 almoxarife, 01 estagiário e 02 fiscais de obras que são contratados pelo Projeto São José. O responsável técnico, de capacitação social e os dois fiscais de obras são contratados e pagos pela Gesar e os demais pelo próprio Sisar.

É administrado pelos seguintes órgãos: uma Assembleia Geral formada por todos os representantes das associações filiadas, um Conselho de Administração formado por onze membros, sendo seis representantes das associações filiadas, eleitos em assembleia geral ordinária para um mandato de três anos, e cinco membros co-participes, sendo um representante da Secretaria de Recursos Hídricos - SRH, um da Secretaria de Desenvolvimento Agrário - SDA; um do Conselho de Políticas e Gestão do Meio Ambiente - CONPAM; um da Cagece e um representante das prefeituras de cada bacia hidrográfica, com o compromisso de colaborar para o crescimento do Sisar-BAJ. Estes membros co-partícipes têm direito a voz e voto nas reuniões do conselho e participam como colaboradores esclarecendo dúvidas e auxiliando as associações filiadas na tomada de decisões; e um Conselho Fiscal, responsável pela fiscalização das ações do Sisar; formado por representantes das associações filiadas, eleitos em assembleia para mandato de dois anos, sendo três membros efetivos e três suplentes, vale salientar que os cargos efetivos do Conselho (presidente, tesoureiro e secretário) obrigatoriamente, são ocupados por representantes das associações filiadas. A assessoria gerencial é feita pela Gesar, com o objetivo de apoiar os oito Sisar's, no acompanhamento e análise dos 
indicadores técnicos, sociais e administrativo-financeiros, buscando a autossustentabilidade do modelo. (SILVA; CORTEZ; RIBEIRO, 2013, p.8)

Para que uma associação ingresse no Sisar, é necessário que esta dê entrada, através de um documento chamado Carta Consulta demonstrando seu interesse em filiar-se. O Sisar realiza uma vistoria criteriosa emitindo um parecer técnico sobre as reais condições do sistema e a legitimidade da associação. Caso não esteja dentro dos critérios, deve se especificar no parecer todas as ações e custos necessários para deixá-lo dentro dos padrões exigidos. Após adequação do sistema, a Carta Consulta, o relatório técnico e os pareceres (técnico e social) são apresentados ao Conselho de Administração do Sisar; e este delibera sobre a filiação da comunidade.

Neste modelo de gestão, a operação do sistema é de responsabilidade da comunidade, através de sua associação local, eles apenas escolhem um sócio para cuidar da operação do sistema. Este operador não é funcionário do Sisar, e sim um colaborador da comunidade, não tendo vínculo empregatício com a mesma, e recebe desta, uma ajuda de custo por este serviço. Os custos são assim discriminados: o custo do Sisar engloba pessoal, logística e todos os insumos de manutenção; já os custos locais incluem o operador, energia e a administração da associação. Com isso tem-se um sistema de tarifa composta em duas partes: a do Sisar é a tarifa pelo volume consumido e o local é uma divisão fixa das despesas. 0 operador, assim como o valor da sua gratificação, é definido pelos próprios usuários do sistema, em assembleia geral da associação local, registrada em seu livro de ata e inserido nas faturas de água. Para o Sisar, fica apenas o valor atribuído ao consumo de água medido pelo hidrômetro, com uma taxa mínima de consumo de 10 mil litros de água $\left(\mathrm{m}^{3}\right)$.

Tabela 1 - Modelo de Fatura Mínima de $10 \mathrm{~m}^{3}$

\begin{tabular}{lr}
\hline DETALHAMENTO & Valores \\
\hline Água $\left(10 \mathrm{~m}^{3}\right)$ & 8,65 \\
Operador & 4,00 \\
Energia & 3,00 \\
Taxa Administrativa & 1,00 \\
Total & 16,65 \\
\hline
\end{tabular}

Fonte: Posseidon (2015), Associação de Ebron 
$\mathrm{Na}$ formulação inicial a cobrança dessas faturas era feita por cada associação local, que centralizava a arrecadação, prestando contas ao Sisar e repassando a parte deste. Diversos problemas de atraso na prestação de contas e ainda alguns casos de desaparecimento do recurso arrecadado sob a alegação de furto, fez com que se mudasse tal sistemática. O Sisar passou a cobrança para terceiros - agentes arrecadadores do tipo bancárias, casas de loterias e estabelecimentos comerciais, invertendo o fluxo financeiro, agora com a arrecadação indo para o SISAR e este repassando para a associação a sua parte.

Com essa arrecadação o Sisar realiza a manutenção preventiva e corretiva, fornece produto químico para o tratamento da água, faz as análises juntamente com a Cagece, realiza ações educativas e dá suporte no gerenciamento local do sistema junto às associações capacitando-as, conforme ilustrado abaixo, alguns sistemas reformados e reestruturados.

Como o serviço de operação dos sistemas é feito pelos operadores de cada comunidade, o quadro funcional do Sisar é reduzido, necessitando somente de uma estrutura de apoio no escritório para confeccionar as contas, realizar manutenções, planejar e gerenciar todas as atividades a serem realizadas. O Sisar capacita os operadores através de treinamento. Na própria conta de água além dos serviços citados anteriormente, também está inserido o valor da energia consumida pelo sistema de acordo com o valor da fatura da Coelce, a qual é rateada, proporcionalmente ao consumo, entre os usuários.

Em relação à estruturação da tarifa implantada pelo Sisar-BAJ se tomou como parâmetros a combinação de dois aspectos de extrema relevância - a necessidade de se obter a autossustentabilidade dos sistemas e as condições socioeconômicas dos usuários observando que cada usuário possa ser conscientizado dos custos sobre cada um dos itens que se apresentam com partes variáveis e não variáveis, facilitando o planejamento do orçamento familiar e possibilitando influir de forma transparente e racional sobre a quantidade de água consumida. A distribuição dos custos é feita pelo serviço e se classifica entre serviços de tarifa fixa e tarifa progressiva. A tarifa fixa é estabelecida de acordo com o número de ligações existentes em cada localidade e rateada por igual para cada usuário, mas este tipo de tarifa é possível apenas em alguns serviços como o de energia, como citado anteriormente. No caso de tarifa progressiva, após os $10 \mathrm{~m}^{3}$ de água consumida, 
registrada pelo hidrômetro, o usuário pagará conforme o seu consumo. Esta última é mais precisa e justa, pois o cliente paga o que consumir, sendo ela a implantada na maior parte das comunidades.

O diferencial deste modelo de gestão está no fato dos usuários serem ao mesmo tempo beneficiários do serviço de abastecimento de água, mas também responsáveis pela gestão do sistema através da representação da associação local junto ao Sisar. Com isso, o Estado e o Município podem expandir os serviços públicos de abastecimento de água na zona rural obtendo melhoria da saúde, reduzindo as migrações das áreas rurais, propiciando infraestrutura para o desenvolvimento do interior pela melhoria das condições de vida da população e fortalecendo a comunidade local.

Desde a sua implantação até os dias atuais o Sisar-BAJ tem apresentado momentos de evolução. Mesmo sendo uma ONG, sem fins lucrativos, o Sisar-BAJ tem apresentado superávit financeiro desde sua implantação, seu desempenho e esforços para a prestação dos serviços de abastecimento rural, juntamente com o apoio das associações, foi positiva e satisfatória se levado em consideração a situação em que viviam nas comunidades abastecidas. A evolução quantitativa do modelo ao longo do tempo não tem sido linear. A expansão do número de localidades filiadas e do atendimento não é constante dado que depende exclusivamente dos investimentos em novos sistemas feitos pelos programas dos governos estaduais

Tabela 2-Localidades assistidas e ligações,2004-2014

\begin{tabular}{c|c|c|c|c|c|c|c|c|c|c|c}
\hline Itens/Ano & 2004 & 2005 & 2006 & 2007 & 2008 & 2009 & 2010 & 2011 & 2012 & 2013 & 2014 \\
\hline Localidades & 18 & 25 & 41 & 44 & 48 & 53 & 58 & 67 & 89 & 93 & 98 \\
\hline Ligações & 2.150 & 3.127 & 4.806 & 5.137 & 6.344 & 7.092 & 7.815 & 8.323 & 11.827 & 12.707 & 13.590 \\
\hline
\end{tabular}

A Tabela acima mostra o crescimento no que diz respeito ao número de localidades filiadas e atendidas pelo Sisar-BAJ, assim como também o número de ligações existentes nas mesmas. Esse crescimento está ligado ao acesso à água de qualidade e, em contrapartida, à má gestão desses recursos que fez com que aumentasse a busca dessa parcela da população pela parceria com esse modelo de gestão. Esse crescimento tem seus pontos positivos e negativos. Por um lado, há a 
melhora na qualidade de vida desses consumidores, pois terão água potável e de qualidade, sem que se faça necessário a busca através meios precários de usufruir esse bem, já em contrapartida, esse crescimento elevado requer um maior investimento em mão de obra qualificada e a busca por meios técnicos específicos o que requer um apoio maios das políticas públicas.

O resultado financeiro deste modelo engloba pelo lado das despesas tudo 0 que se refere à administração/comercialização, operação e manutenção dos sistemas filiados. A seguir, podemos observar a evolução financeira com dados disponibilizados a partir do ano de 2004, com um superávit em todos os anos, o que caracteriza o Sisar-BAJ como um modelo de gestão autossustentável.

Figura 3- Indicadores Financeiros, 2004-2014

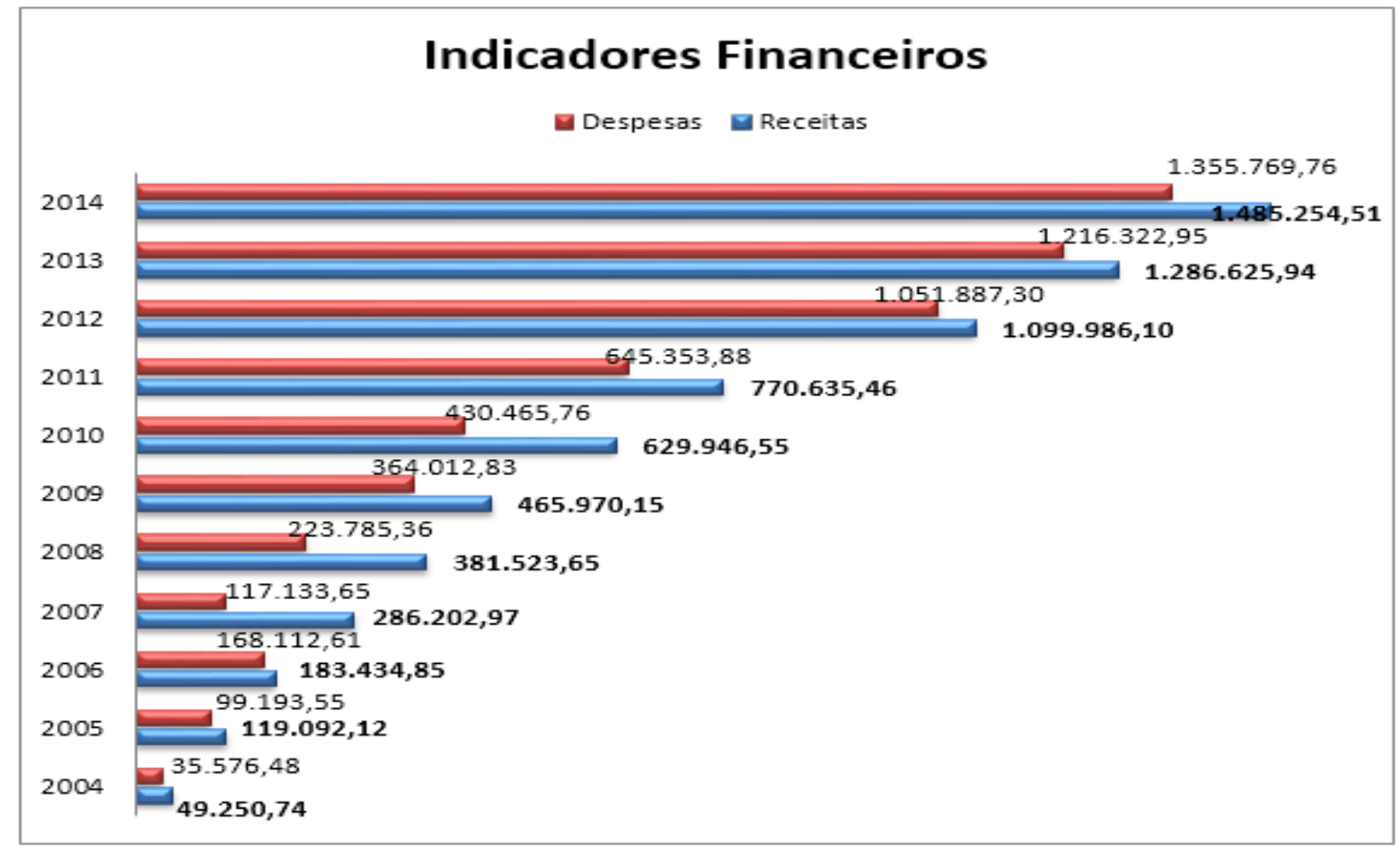

Fonte: Posseidon (2015)

Em termos de evolução qualitativa pode-se dizer que o modelo teve relativo sucesso em sua trajetória, o que pode ser avaliado pelos indicadores disponíveis. Estes resultados têm evoluído positivamente ao longo dos anos de forma diferenciada. Isto ocorre pela maior ou menor amplitude de atendimento de cada uma das comunidades, o que reflete na economia de escala do modelo. Infelizmente, o país ainda não conta com um plano ou programa específico para os 
serviços rurais. Os investimentos federais não exigem que a gestão dos sistemas se faça por modelo sustentável, e deste modo não existe ainda, pelo Governo Federal, incentivo para expansão do Sisar e nem mesmo indução à adesão nas regiões onde existe o modelo. Os exemplos existentes deram-se por iniciativas dos respectivos Governos Estaduais incentivados pelo organismo financiador, o KFW. Assim como faz falta uma política federal para os serviços rurais, fica clara a necessidade de institucionalização dos modelos existentes também ao nível dos estados. Isso significa que o aporte estadual de apoio à gestão dos serviços rurais precisa ser instituído em instrumento de política, legislação e programas de investimento específicos que tenham um modelo sustentável como o Sisar.

\section{CONSIDERAÇÕES FINAIS}

Como vimos, o modelo Sisar tem evoluído de forma restrita à região nordeste do país e o incentivo ao modelo tem surgido por iniciativa de programas restritos aos governos estaduais, já no âmbito federal, não existe um programa de investimento específico para os serviços rurais. No caso do Ceará, sabe-se que o suporte dado pela Cagece não está amparado em instrumentos legais e em um formato institucional estadual mais sólido. Sendo a Cagece empresa de economia mista, existe forte risco de que ocorrendo mudança empresarial, seja por orientação política, ou seja, por abertura de seu capital no mercado, o atual apoio pode deixar de existir. É fundamental que o suporte e o subsídio sejam do Estado, mesmo que possam ser operacionalizados por uma empresa estadual prestadora de serviço. Ainda que tendo assento nos conselhos das unidades do Sisar, o interesse demonstrado e o grau de atuação dos executivos municipais são restritos. Contudo, este nível federativo torna-se ativo quando estimulado pelo governo estadual, o que indica que na formulação de políticas e programas estaduais voltadas ao meio rural devem ser buscados mecanismos ágeis de inserção do poder municipal. Assim como faz falta uma política federal para os serviços rurais, fica patente a necessidade de institucionalização dos modelos existentes também ao nível dos estados. Isto significa que o aporte estadual de apoio à gestão dos serviços rurais precisa ser instituído em instrumentos de política, legislação e programas de investimento específico que tenham endereço em modelo sustentável como o Sisar. 
Pode-se assegurar que o Sisar é um exemplo de sucesso. O modelo no Ceará pode-se afirmar como o de melhor desempenho por possuir uma sustentabilidade estrutural e as razões disto pode estar resumido como aspecto determinante o aporte tecnológico e de gestão empresarial fornecido pela Cagece e em contrapartida deste apoio está o monitoramento exercido pela mesma das metas de desempenho do Sisar, outro fato é a capacidade do estado em dar continuidade aos investimentos nas comunidades rurais e que permite a expansão do modelo dando ganho de escala e sustentabilidade às unidades em todo o estado.

Assim o Sisar surge para garantir o sucesso do autogerenciamento dos sistemas implantados, uma vez que as mesmas se encontravam desvinculadas e desarticuladas entre si e, portanto, frágeis e sem condições de auto-gerir um projeto tão abrangente. Devido ao suporte do SISAR, a operação local é de boa qualidade tanto em continuidade da distribuição quanto em portabilidade da água, a sustentabilidade tem sido alcançada gradativamente conforme se amplia o atendimento de cada unidade, contudo ela se dá em termos exclusivos da cobertura dos custos de administração, operação e manutenção, não incluindo remunerar os custos de capital. Contudo, mesmo para o custo operacional permanece o subsídio ao modelo, onde existem o subsídio direto (que cobre parte dos custos) e o indireto (apoio e assessoramento), ambos pagos pela Cagece (companhia estadual de água e esgoto); além disto, o permanente processo de capacitação em associativismo fortalece a estrutura das associações locais. Mas o modelo federativo necessita que ações sejam feitas pelos governos, entre as quais: formulação de plano, programas de investimento e marco institucional; existir órgão estadual de aporte tecnológico e empresarial; sistema de metas de desempenho; sistema de informações sobre o meio rural e modernização do cadastro técnico do Sisar e incentivo à replicação do modelo nas demais regiões do país viabilizando a formalização legal da mão de obra local.

Infelizmente, o país ainda não conta com um plano ou programa eficiente para os serviços rurais. Os investimentos federais não exigem a gestão dos sistemas se faça por modelo sustentável, e deste modo não existe ainda pelo Governo Federal incentivo para expansão do Sisar e nem mesmo indução à adesão nas regiões onde existe o modelo. Os exemplos existentes deram-se por iniciativas dos respectivos Governos Estaduais incentivados pelo organismo financiador, o KFW. 
Assim como faz falta uma política federal que invista de forma contundente nos serviços rurais, fica clara a necessidade de institucionalização dos modelos existentes também ao nível dos estados. Isso significa que o aporte estadual de apoio à gestão dos serviços rurais precisa ser instituído em instrumento de política, legislação e programas de investimento específicos que tenham um modelo sustentável como o Sisar.

\section{REFERÊNCIAS}

ASSOCIAÇÃO BRASILEIRA DE NORMAS TÉCNICAS. NBR 6023: informação e documentação: referências: elaboração. Rio de Janeiro, 2002.

BRASIL. (2007) Lei Federal no 11.445, de 5 de janeiro de 2007. Estabelece diretrizes nacionais para o saneamento básico. Diário Oficial da União, Brasília, 5 jan.

2007.Disponívelem:<http://www.planalto.gov.br/ccivil_03/_ato20072010/2007/lei/l114 45.htm>. Acesso em: 13 mar. 2019

CAGECE. CORTEZ, Helder. SISAR - Sistema de Saneamento Rural Cearense é referência. O Estado CE, Fortaleza, 26 fev. 2014.

INSTITUTO TRATRA BRASIL (ITB). (2016) Ranking do Saneamento. Relatório Completo. São Paulo: ITB.

INSTITUTO TRATRA BRASIL (ITB). (2018) Benefícios Econômicos e Sociais do Saneamento no Brasil. Completo. São Paulo: ITB.

MAGALHÃES, R. L.; BARBOSA, O. S. P.; OLIVEIRA, B. L. Saneamento Ambiental em Áreas Rurais: novas propostas de organização da sociedade. XVI Encontro Nacional dos Geógrafos, Porto Alegre, 30 jul. 2010.

PAIVA. A. L. Nogueira de. Consórcios Intermunicipais: Mapeando a Cooperação entre Municípios para a Gestão dos Serviços de abastecimento de água e Esgotamento Sanitário. XX Simpósio Brasileiro de Recursos Hídricos, Bento Gonçalves - Rio Grande d Sul, 22 nov. 2013.

RESENDE, R. G. O saneamento rural no contexto brasileiro Revista Agrogeoambiental, Pouso Alegre, v. 10, n. 1, mar. 2018

ROCHA, S. WILSON. Estudo de caso do Sistema Integrado de Saneamento Rural (SISAR) no Brasil. BID-Setor de Infraestrutura e Meio Ambiente. IDBTN589[S.I.:s.n], 2013. 77p. 
SILVA, J. M.; CORTEZ, H. S. e; RIBEIRO, O. A. SISAR o modelo de gestão para a universalização do Saneamento Rural no Ceará. Fortaleza, 2013.

SILVA, Joana Marinho e; CORTEZ, Helder dos Santos. O Modelo de Gestão para o Saneamento Rural no estado do Ceará. Fortaleza, 2011.

SISAR-BAJ, Sistema Integrado de Saneamento Rural da Bacia do Alto Jaguaribe. Banco de Dados Posseidon. Acopiara, 2015.

TUROLLA, F.A. Indefinições no saneamento. São Paulo: Conjuntura da Construção, ano 3, n.1, mar. 2005. 9-12p. (Separata da Conjuntura Econômica SindusCon- SP/FGV-EESP 